\title{
Comparison of dual chamber and ventricular rate responsive pacing in patients over 75 with complete heart block
}

\author{
M R Hargreaves, K M Channon, T R Cripps, M Gardner, O J M Ormerod
}

\begin{abstract}
Objective-To compare symptoms and exercise tolerance during dual chamber universal (DDD) and ventricular rate response (VVIR) pacing in elderly $(\geqslant 75)$ patients.
\end{abstract}

Design-Randomised, double blind, crossover study.

Setting-Regional cardiac department.

Patients-Twenty elderly patients (mean age 80.5 (1) years) with high grade atrioventricular block and sinus rhythm. Patients with pre-existing risk factors for the pacemaker syndrome and chronotropic incompetence were excluded.

Intervention-After four weeks of VVI pacing following pacemaker implantation, patients underwent consecutive two week periods of VVIR and DDD pacing.

Main outcome measures-Patient preference, symptom scores, "daily activity exercises," and perceived level of exercise (Borg score).

Results-Eleven patients preferred DDD mode to either VVI or VVIR mode. Mean (SE) total symptom scores during VVI, VVIR, and DDD pacing were $5.9(1 \cdot 1)$, $6 \cdot 1(1 \cdot 0)$, and $3 \cdot 5(0 \cdot 9)$ respectively $(P<0.01)$. The corresponding mean (SE) pacemaker syndrome symptom scores were $4.8(0.7), 5.2(0.8)$, and $2.9(0.8)$ $(P<0.05)$. Symptom scores during VVI and VVIR pacing were not significantly different. Exercise performance and Borg scores were significantly worse during VVI pacing compared with VVIR or DDD pacing but did not significantly differ between VVIR and DDD modes.

Conclusions-In active elderly patients with complete heart block both DDD and VVIR pacing are associated with improved exercise performance compared with fixed rate VVI pacing. The convenience and reduced cost of VVIR systems, however, may be offiset by a higher incidence of the pacemaker syndrome. In elderly patients with complete heart block VVIR pacing results in suboptimal symptomatic benefit and should not be used instead of DDD pacing.

(Br Heart f 1995;74:397-402)

Keywords: dual chamber pacing; ventricular rate responsive pacing; complete heart block

There is general agreement that dual chamber pacemakers (DDD) should be considered for all patients with advanced atrioventricular block and sinus rhythm. ${ }^{1}$ Compared with single chamber ventricular pacing (VVI), there are established benefits in haemodynamics, ${ }^{23}$ symptoms, and exercise performance. ${ }^{45}$ Single chamber rate responsive pacing (VVIR) has also been shown to improve haemodynamics 6 and exercise performance ${ }^{78}$ compared with VVI pacing. It has therefore been suggested that in selected patients VVIR may be an acceptable alternative to DDD pacing. ${ }^{9}$ VVIR pacemakers are easier to insert than dual chamber systems and require less follow up: the rate response settings may need little attention after implantation. ${ }^{8}$ In addition, although atrial activity is not sensed, the rate response function ensures that exercise capacity is maintained at a level comparable with DDD pacemakers. ${ }^{9-11}$ Finally, the average price of a VVIR system is considerably less than that of a DDD system. Potential disadvantages of VVIR pacing, however, include loss of atrial synchrony and development of the pacemaker syndrome.

One earlier study reported little subjective difference between DDD and VVIR pacing," but subsequent within patient comparisons have shown lower symptom scores and improved quality of life during DDD pacing compared with VVIR pacing. ${ }^{101213}$ There is general agreement, however, that both DDD and VVIR modes lead to similar improvements in exercise tolerance..$^{9-11}$

In the United Kingdom the median age of patients referred for pacemaker implantation during 1993 was 76 years; $55 \%$ of all patients were aged over 75 years and $37 \%$ were aged over 80 years (British Pacing and Electrophysiology Group, personal communication). However, most patients enrolled in contemporary studies comparing VVIR and DDD pacing are under 75 years of age. Thus recommendations based on these studies may not necessarily be applicable to elderly patients with pacemakers. Age related changes in the cardiovascular system, for example, may render elderly people less tolerant of the loss of atrioventricular synchrony associated with VVIR pacing. ${ }^{14-16}$

The primary objective of the study was to compare symptoms and exercise tolerance during DDD and VVIR pacing in elderly patients with complete heart block. A secondary objective was to identify possible clinical or echocardiographic predictors of VVIR intolerance. 
Table 1 Characteristics of study patients

\begin{tabular}{|c|c|c|c|c|c|}
\hline $\begin{array}{l}\text { Case } \\
\text { No }\end{array}$ & Sex & $\begin{array}{l}\text { Age } \\
\text { (years) }\end{array}$ & Other medical conditions & Drug treatment & $\begin{array}{l}\text { Ejection } \\
\text { fraction (\%) }\end{array}$ \\
\hline 1 & $\mathbf{F}$ & 75 & Claudication osteoarthritis & Aspirin & 40 \\
\hline $2^{\star \star} \dagger$ & $\mathbf{M}$ & 75 & None & None & 72 \\
\hline 3 & $\mathbf{M}$ & 83 & Osteoarthritis & None & 50 \\
\hline 4 & $\mathbf{M}$ & 83 & Asthma, hypertension, previous mild stroke & Bronchodilators, aspirin & 53 \\
\hline 5 & $\mathbf{M}$ & 80 & Hypertension, acromegaly & Co-amilofruse & 77 \\
\hline $6 \dagger \ddagger$ & $\mathbf{M}$ & 84 & None & None & 65 \\
\hline 7 & $\mathbf{M}$ & 75 & Emphysema & Bronchodilators, steroids & 59 \\
\hline $8+\ddagger$ & $\mathbf{M}$ & 83 & Gout, hypertension & Nifedipine & 65 \\
\hline $9 \dagger$ & $\mathbf{F}$ & 75 & Angina & None & 78 \\
\hline 10 & $\mathbf{M}$ & 81 & None & None & 62 \\
\hline 11 & $\mathbf{F}$ & 86 & Hypertension & Nifedipine, bendrofluazide & $\mathbf{n} / \mathbf{a}$ \\
\hline 12 & $\mathbf{M}$ & 80 & Rheumatoid arthritis, diabetes & None & 65 \\
\hline 13 & $\mathbf{F}$ & 81 & Hypertension & Enalapril & 60 \\
\hline $14 \ddagger$ & $\mathbf{M}$ & 77 & Diabetes & None & $\mathbf{n} / \mathbf{a}$ \\
\hline 15 & $\mathbf{M}$ & 89 & Osteoarthritis, hypertension & Enalapril, bendrofluazide & 63 \\
\hline 16 & $\mathrm{~F}$ & 75 & None & None & 75 \\
\hline $17 \ddagger$ & $\mathbf{M}$ & 85 & Mild asthma & Bronchodilators & $\mathrm{n} / \mathbf{a}$ \\
\hline 18 & $\mathbf{M}$ & 84 & Gout & None & 53 \\
\hline 19 & $\mathbf{M}$ & 83 & Osteoarthritis & None & 55 \\
\hline 20 & $\mathrm{~F}$ & 76 & None & None & 58 \\
\hline
\end{tabular}

* Developed retrograde conduction. †Requested early crossover for VVIR

$\ddagger$ Developed 1:1 anterograde atrioventricular conduction before first visit.

\section{Patients and methods}

We studied 20 consecutive patients aged 75-89 (mean 80.5 (1.0) years; 14 men) who had been referred for permanent pacemaker implantation. Patients were eligible if $(a)$ they were aged over $75,(b)$ an electrocardiogram before implantation showed sinus rhythm and complete heart block of at least 7 days' duration, and $(c)$ they had previously been able to carry out independently the daily activity tests described below. Exclusion criteria included pre-existing indications for the maintenance of atrial synchrony-for example, left ventricular dysfunction - evidence of retrograde atrioventricular conduction at implantation, and chronotrophic incompetence. Informed consent was obtained from each patient, and the study was approved by the local research ethics committee. Basic demographic data are presented in table 1 .

\section{STUDY DESIGN}

The study was a double blind, two period, crossover comparison of DDD and VVIR pacing modes. Eligible patients received a Biotronic Ergos 03 dual chamber pacemaker (DDDR) and were discharged from hospital with it in VVI pacing mode. After a month each patient returned to be assessed by questionnaire and to undertake exercise testing in VVI mode in order to familiarise themselves with the study protocol and provide baseline data. Patients also underwent a symptom limited treadmill test (modified Bruce protocol) in DDD pacing mode to assess the chronotropic response to exercise. ${ }^{17}$ Patients with chronotropic incompetence were withdrawn. Patients were then randomly allocated either VVIR or DDD pacing (mode 1). After two weeks their response to mode 1 was assessed by questionnaire and exercise testing before their pacemakers were reprogrammed to the alternative mode (mode 2). At the final visit exercise testing and questionnaires were repeated and the patients were asked which study period, if any, they had preferred. Finally, patients were returned to DDD mode and echocardiography was performed. The ejection fraction was calculated by the arealength method. ${ }^{18}$

\section{PACEMAKER PROGRAMMING}

In all three modes the lower and upper rates were set, when applicable, at 72 and 125 beats/minute respectively. ${ }^{19}$ The a-v delay was set at $175 \mathrm{~ms}$. In VVIR mode the rate response threshold was set at medium and the curve between 6 and 8 . The final setting was determined by the sinus response during treadmill exercise (visit 1 ).

\section{SYMPTOM QUESTIONNAIRES}

At each visit patients were asked by questionnaire whether they had experienced symptoms during the preceding two weeks and, if so, to what extent. ${ }^{20}$ Symptoms suggestive of the pacemaker syndrome (breathlessness, pulsation, dizziness, blackout, wheeze, fatigue, palpitation, and cough) were included in a list with control symptoms (headache, chest pain, diarrhoea, vomiting, apprehension, leg cramps, cough, dysuria). Patients were asked to indicate the severity of each symptom on an analogue scale marked from 0 to $5(0$, none; 1 , very mild; 2 , mild; 3 , moderate; 4 , quite severe; 5 , very severe).

\section{EXERCISE TESTING}

At each visit patients underwent three simple exercise tests corresponding to the daily activities of elderly patients. The exercises were supervised by the same investigator for each patient and followed the same order.

(1) Stand ups from a chair. Patients were asked to stand up and sit down from a standard chair as many times as possible for two minutes.

(2) Walking. Patients walked as briskly as possible back and forth along a measured length (approximately $25 \mathrm{~m}$ ) of corridor, turning around at the end of each length. The total number of lengths walked in six minutes, or the maximum number attained by the patient before asking to stop, was recorded.

(3) Stair climbing. Patients were timed how quickly they could ascend two flights of stairs (26 steps), using a stair rail if necessary.

The heart rate at peak exercise was determined immediately after exercise by an automated heart rate monitor. Patients were asked to grade how difficult they had perceived each 
Table 2 Effect of pacing order on symptom scores, exercise performance, and total Borg scores. Values are means (SE)

\begin{tabular}{|c|c|c|c|c|c|c|}
\hline & \multicolumn{3}{|c|}{ Pacing order (11 patients): } & \multicolumn{3}{|c|}{ Pacing order (9 patients): } \\
\hline & $V V I$ & $D D D$ & $V V I R$ & $V V I$ & VVIR & $D D D$ \\
\hline \multicolumn{7}{|l|}{ Symptom score: } \\
\hline Total & $6 \cdot 5(2)$ & $3.6(1)^{\star}$ & $7 \cdot 6(1)$ & $5 \cdot 0(1)$ & $4 \cdot 6(1)$ & $3 \cdot 4(1)$ \\
\hline Pacemaker syndrome & $4 \cdot 7(1)$ & $2 \cdot 9(1)^{\star}$ & $6 \cdot 3(1)$ & $4 \cdot 7(1)$ & $3.9(1)$ & $2 \cdot 7(2)$ \\
\hline \multicolumn{7}{|l|}{ Exercise performance: } \\
\hline No of stand ups in 2 minutes & $36(4)^{\star \star}$ & $44(5)$ & $43(6)$ & $35(5) \dagger$ & $40(5)$ & $42(5)$ \\
\hline No of lengths walked in 6 minutes & $18(2)$ & $20(1)$ & $20(1)$ & $18(2)$ & $18(2)$ & $20(2)$ \\
\hline Time to climb 26 steps(s) & $15(1)$ & $14(1)^{\star}$ & $15(1)$ & $19(3)$ & $17(2)$ & $16(3)$ \\
\hline Total Borg score & $37(1)$ & $34(2)$ & $37(1)$ & $35(2)$ & $35(2)$ & $33(2)$ \\
\hline
\end{tabular}

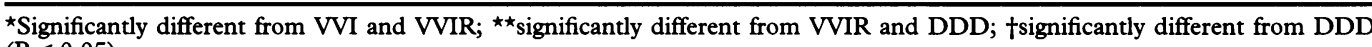
$(\mathrm{P}<0.05)$.

exercise according to the Borg symptom score, scores being from 6 (very, very light) to 20 (very, very hard) with corresponding word prompts for the numbers in between.

\section{STATISTICAL ANALYSIS}

All results are expressed as means (SE). Means were compared by an analysis of variance. The differences between means were detected by Fisher's least significant difference test. A $P$ value less than 0.05 was regarded as significant. The study size was calculated from data derived from a previous investigation. ${ }^{20}$ With type I and II errors set at 0.1 and 0.05 respectively there was sufficient power to detect a four point change in pacemaker symptom score, a $20 \%$ change in total Borg score, and a $25 \%$ change in exercise capacity. The study was analysed on an intention to pace basis; we included patients who developed spontaneous return of anterograde conduction, but we also performed an analysis excluding them.

\section{Results}

Four patients spontaneously regained anterograde atrioventricular conduction between pacemaker implantation and the initial study visit. In these patients the pacemaker was inhibited by the resting sinus rate during VVI
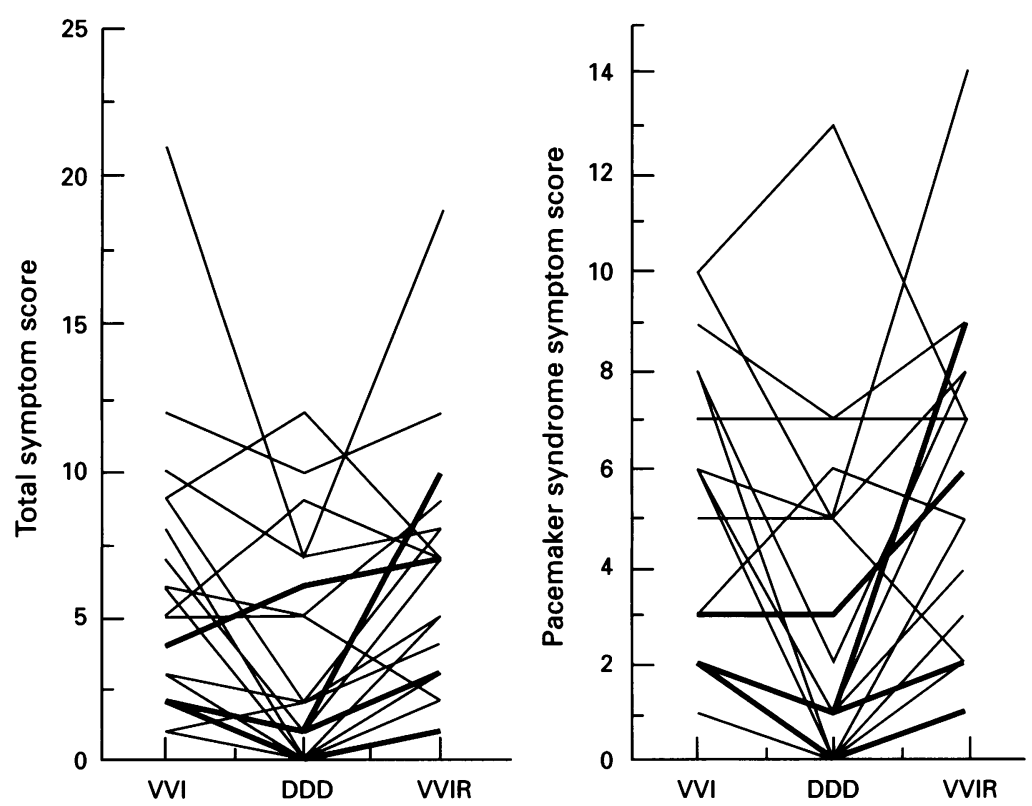

Figure 1 Individual total symptom and pacemaker syndrome symptom scores during VVI, DDD, and VVIR pacing. Thickened lines represent patients with intact anterograde atrioventricular conduction. mode. In two of these patients the ventricles were paced during exercise in VVIR mode, resulting in the development of the pacemaker syndrome.

One patient developed retrograde conduction during the VVIR study that was associated with significant symptomatic deterioration. Three patients requested early crossover from VVIR pacing owing to intolerable symptoms. Overall, 11 patients preferred DDD mode to the other two modes. One patient each preferred VVI and VVIR mode and seven did not express a preference.

The mean period effect on total symptom and pacemaker syndrome symptom were 1.4 and $1 \cdot 1$ respectively $(P>0.05)$. There was no significant treatment and period interaction. The effects of pacing order-that is, DDD followed by VVIR or vice versa- on symptom scores, exercise performance, and Borg scores are shown in table 2. Symptomatically, patients tolerated VVIR pacing better if they had not been previously exposed to DDD pacing. Exercise tolerance and Borg scores, however, were not influenced by the order of pacing.

\section{SYMPTOMS}

Mean total symptom scores during VVI, VVIR, and DDD pacing were $5 \cdot 9(1 \cdot 1), 6 \cdot 1$ $(1.0)$, and $3.5(0.9)$ respectively $(P<0.01)$. The corresponding pacemaker syndrome symptom scores were $4.8(0.7), 5 \cdot 2(0.8)$, and $2.9(0.8)(P<0.05)$. The scores for individual patients are shown in figure 1 . Both scores were significantly reduced during DDD mode compared with VVI and VVIR modes $(\mathrm{P}<$ $0.05)$. Symptom scores during VVI and VVIR modes were not significantly different. When the four patients with anterograde atrioventricular conduction were excluded the total symptom scores were $6 \cdot 8(1 \cdot 3), 6 \cdot 3(1 \cdot 1)$ and $3.9(1.0)$ for VVI, VVIR, and DDD modes respectively $(P<0.01)$. The corresponding pacemaker syndrome symptom scores were $5.4(0.8), 5.4(0.9)$, and $3.3(0.9)(P<0.05)$.

\section{EXERCISE PERFORMANCE AND PERCEIVED} EXERCISE DIFFICULTY

For each test, exercise performance was better in the rate-response modes (DDD and VVIR) than with VVI pacing. In contrast to symptom scores, exercise performance during DDD and VVIR modes was similar. Maximum heart rates after each exercise were similar in the two rate-response modes. These results are detailed in tables 3 and 4. 
Table 3 Exercise test performances and respective Borg scores during VVI, VVIR, and $D D D$ pacing modes. Values are means (SE)

\begin{tabular}{|c|c|c|c|c|c|c|}
\hline \multirow[b]{2}{*}{ Mode } & \multicolumn{2}{|c|}{ Stand ups } & \multicolumn{2}{|l|}{ Walking } & \multicolumn{2}{|c|}{ Climbing 26 steps } \\
\hline & No & Borg score & No of lengths & Borg score & Time(s) & Borg score \\
\hline $\begin{array}{l}\text { VVI } \\
\text { VVIR } \\
\text { DDD }\end{array}$ & $\begin{array}{l}35(3)^{\star} \\
41(4) \\
42(3)\end{array}$ & $\begin{array}{l}13(1) \\
13(1) \\
12(1)\end{array}$ & $\begin{array}{l}18(1)^{\star} \\
19(1) \\
20(1)\end{array}$ & $\begin{array}{l}12(1) \\
11(1) \\
11(1)\end{array}$ & $\begin{array}{l}17(1) \\
16(1) \\
15(1)^{\star \star}\end{array}$ & $\begin{array}{l}11(1) \\
12(1) \\
11(1)\end{array}$ \\
\hline
\end{tabular}

*Significantly different from VVIR and DDD mode $(\mathrm{P}<0.05)$.

$\star \star$ Significantly different from VVI $(P<0.01)$.

Total Borg scores (SE) during VVI, VVIR, and DDD modes were $35.7(1.3), 33.5(1.4)$, and $35.8(1 \cdot 1)$ respectively $(P=0.06)$. The Borg values for each exercise test are shown in table 3.

\section{ECHOCARDIOGRAPHIC DATA}

Echocardiographic data were available in 17 patients. Mean (SE) left ventricular systolic and diastolic dimensions were $34.9(1.5) \mathrm{mm}$ and $54.2(1 \cdot 2) \mathrm{mm}$ respectively. The mean ejection fraction was $61 \cdot 8 \%(2 \cdot 5 \%)$. There was a significant correlation between resting ejection fraction (DDD mode) and total $\left(r^{2}=\right.$ $0.38, \mathrm{P}<0.01)$ and pacemaker symptom $\left(r^{2}\right.$ $=0.29, \mathrm{P}<0.05)$ scores during baseline VVI pacing (fig 2). However, the association was not strong enough to allow accurate prediction of VVI intolerance or preference. Mean left atrial size was $38(1 \cdot 1) \mathrm{mm}$ (range 32-49 $\mathrm{mm}$ ). There was no correlation between left atrial size and any symptom score or derivative.

\section{Discussion}

In our elderly population both total and pacemaker syndrome symptom scores were significantly lower during DDD mode compared with VVI and VVIR modes. There was no difference in symptom scores between VVI and VVIR pacing modes. In terms of exercise performance and the perceived level of exercise (Borg score), however, we observed no overall difference between the two rate-response modes. Both rate-response modes (DDD and VVIR) were significantly better than baseline VVI pacing.

Figure 2 Relation between resting ejection fraction ( $D D D$ mode) and total symptom score during VVI mode

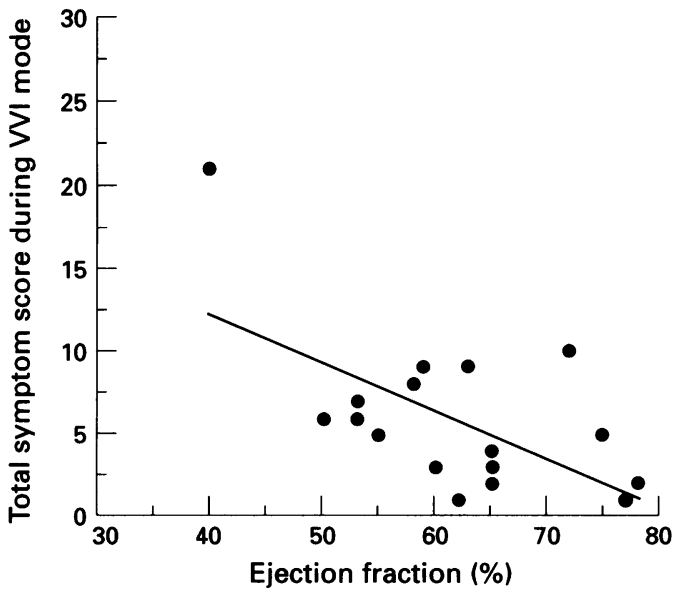

Table 4 Mean (SE) heart rates (beats/minute) during VVI, VVIR, and DDD pacing modes for each exercise

\begin{tabular}{llll}
\hline Exercise & $V V I$ & $V V I R$ & $D D D$ \\
\hline Stand ups & $82(5)^{\star}$ & $106(4)$ & $107(4)$ \\
Walking & $80(3)^{\star}$ & $113(3)$ & $109(4)$ \\
Climbing stairs & $81(4)^{\star}$ & $112(3)$ & $111(4)$ \\
\hline
\end{tabular}

^Significantly different from VVIR and DDD, $(P<0.001)$

\section{SYMPTOM SCORES}

Previous crossover studies within patients have compared symptoms and exercise performance during DDD and VVIR pacing modes. Sulke et al reported symptomatic deterioration during VVIR compared with DDD pacing within a fairly young population (mean age 52 (4)). ${ }^{11}$ Menozzi et al likewise reported significant symptomatic deterioration during VVIR pacing in a group of older patients (mean age $72(6)) .{ }^{10}$ In this study there was substantial variation in the individual responses to VVIR pacing; five (36\%) patients reported severe symptoms and requested early crossover while a further six $(43 \%)$ reported no difference between the two pacing modes. ${ }^{10}$ In contrast, we found that most of our patients $(80 \%)$ reported deterioration in symptoms during VVIR compared with DDD pacing. One of the patients who reported improved symptoms during VVIR pacing had significant obstructive airways disease and was aware of an uncomfortable resting tachycardia (sinus rate 100 beats/minute) when atrial tracking (DDD mode). His symptomatic tachycardia, presumably related to his regular bronchodilator treatment, was abolished during VVIR pacing.

The subjective response to VVIR pacing was highly dependent on whether there had been previous exposure to dual chamber pacing. For example, in the 11 patients who had been randomly allocated DDD mode then VVIR mode we observed substantial symptomatic deterioration when these patients were re-exposed to single chamber pacing (VVIR). Seven of the 11 patients who preferred DDD mode came from this group, along with two of the three patients who requested early crossover from VVIR mode. In contrast, nine patients initially exposed to VVIR pacing reported symptomatic improvement compared with baseline VVI. These observations are similar to those of Sulke et al, who compared VVI, DDI, and DDD pacing modes in a group of apparently symptom free patients with long term VVI pacemakers. ${ }^{21}$ We also observed that exercise tolerance was not significantly influenced by the pacing order. Freed from the worry of syncope after having had a pacemaker implanted, most patients are much improved with simple VVI pacing. Although some patients will develop overt pacemaker syndrome, most will remain without complaint, unaware of the symptomatic benefits associated with physiological (dual chamber) pacing. It is only after exposure to dual chamber pacing that the high incidence of subclinical pacemaker syndrome in these patients becomes apparent. ${ }^{21}$ 
Oldroyd et al observed no difference in overall symptoms between DDD and VVIR pacing modes in 10 patients (mean age 56; range $23-74) .{ }^{9}$ Important age related cardiovascular changes may render elderly people less tolerant of non-physiological-that is, VVIR pacing. Left ventricular compliance decreases with advancing age, ${ }^{14}$ increasing the dependence of cardiac output on atrial filling during late diastole. ${ }^{15}$ Corrective cardiovascular reflexes, such as the baroreflexes, may be attenuated with advancing age, thereby increasing the risks of hypotension and of the pacemaker syndrome. ${ }^{16}$ In the studies by Sulke et $a l^{10}$ and Menozzi et $a l^{11}$ and in our study, the symptom questionnaire was specifically designed to detect symptoms suggestive of the pacemaker syndrome-for example, palpitations, pulsation, and dizzinesswhereas the questionnaire (McMaster) used in Oldroyd's study does not specifically ask about the pacemaker syndrome and may have underestimated these symptoms.

Anterograde atrioventricular conduction returned in four $(20 \%)$ patients after implantation. Although comfortable at rest, two of these patients experienced palpitations and dyspnoea (the pacemaker syndrome) during exercise in VVIR mode but not in DDD mode. In these circumstances the pacemaker syndrome arises when the rate-response function drives the ventricular rate higher than the natural sinus rate. ${ }^{22} 23$ Despite symptoms of exercise induced pacemaker syndrome, the overall exercise tolerance of these patients was similar to that during DDD mode. Exclusion of these patients from the analysis did not significantly change the overall findings of the study.

\section{EXERCISE PERFORMANCE}

Our observations confirm previous reports of improved exercise capacity in the elderly during either DDD $^{20} 24$ or VVIR pacing modes ${ }^{8}$ compared with fixed rate VVI pacing. However, most studies that have directly compared DDD and VVIR modes have reported no significant difference in exercise performance. ${ }^{910}$ The contribution of atrial filling to stroke volume increases with advancing age, particularly so during submaximal exercise, ${ }^{25}$ and we had hypothesised that both exercise performance and the perceived level of exercise (Borg scores) in our group of elderly patients would be improved during DDD pacing compared with VVIR pacing. Although we found a trend towards a benefit from DDD pacing, the difference was not significant.

Failure to detect an important difference is unlikely to be a type II error since the power of the sample size was sufficient to detect at least a $25 \%$ change in the performance of each test. Neither can these observations be explained by the exercise heart rates as these were well matched for each test. Alternatively, the findings may be partly explained by a selection bias which favoured enrolment of comparatively fit elderly subjects with more cardiovascular reserve who were able to com- pensate for the loss of atrial contraction during VVIR pacing. Patients in whom there was considered to be a relatively strong indication for dual chamber pacing - for example, a history of heart failure-were not recruited, as borne out by the normal echocardiographic left ventricular dimensions. Selection bias towards fitter elderly patients may also have resulted from the study design, which required three separate visits to the department and extended travelling distances.

\section{RETROGRADE ATRIOVENTRICULAR CONDUCTION}

The development of retrograde atrioventricular conduction in one of our patients (during VVIR mode pacing) was heralded by significant deterioration in symptoms. Similarly, in the study of Oldroyd et al the only patient to request early crossover from VVIR to DDD mode was the only patient with intact retrograde conduction. ${ }^{9}$ The nine other patients without retrograde conduction reported no deterioration in symptoms during VVIR pacing. The authors concluded "that it would be appropriate to consider VVIR activity sensing pacemakers... in patients with complete anterograde and retrograde heart block and preserved ventricular function."9 Although retrograde conduction may be a risk factor for the development of the pacemaker syndrome, ${ }^{26}$ the absence of retrograde conduction at pacemaker implantation does not preclude its subsequent development. ${ }^{27} 28$ Furthermore, the presence of ventriculoatrial conduction has limited utility as a predictor of the pacemaker syndrome in individual patients. ${ }^{1120}$

\section{CLINICAL IMPLICATIONS}

In active elderly patients with complete heart block both DDD and VVIR pacing are associated with improved exercise performance compared with fixed rate VVI pacing. Although VVIR pacing may be adequate in some patients, the convenience and reduced cost of these systems may be offset by the high incidence of the pacemaker syndrome. On the basis of these observations we conclude that VVIR pacing in elderly subjects with complete heart block results in suboptimal symptomatic benefit and should not be used instead of DDD pacing.

MRH and KMC are funded by the British Heart Foundation.

1 British Pacing and Electrophysiology Group. Recommendations for pacemaker prescription for symptomatic mendations for pacemaker prescription for
bradycardia. Br Heart $\mathcal{F} 1991 ; 66: 185-91$.

2 Samet PHBW, Nathan NA, Lopez A. Atrial contribution to cardiac output in complete heart block. Am $₹$ Cardio 1965;16:1-10

3 Karloff I. Haemodynamic effect of atrial triggered versus fixed rate pacing at rest and during exercise in complete heart block. Acta Med Scand 1975;197:195-206.

4 Perrins JE, Morley CA, Chan SL, Sutton R. Randomised controlled trial of physiological and ventricular pacing. Br Heart f 1983;50:112-7.

5 Kruse I, Arnman K, Conradson T, Ryden L. A comparison of the acute and long-term hemodynamic effects of ventricular inhibited and atrial synchronous ventricular inhibited pacing. Circulation 1982;65:846-55.

6 Benditt DG, Mianulli M, Fetter J, et al. Single-chamber cardiac pacing with activity-initiated chronotropic response: evaluation by cardiopulmonary exercise testing. Circulation 1987;75:184-91. 
7 Lipkin DP, Buller N, Frenneaux M, et al. Randomised crossover trial of rate responsive Activitrax and conventional fixed rate ventricular pacing. $B r$ Heart $f$ 1987;58:613-6.

8 Gammage M, Schofield S, Rankin I, Bennett $M$, Coles $P$, Pentecost B. Benefit of single setting rate responsiv ventricular pacing compared with fixed rate demand pacing in elderly patients. PACE Pacing Clin Electrophysiol 1991;14:174-5.

9 Oldroyd KG, Rae AP, Carter R, Wingate C, Cobbe SM Double blind crossover comparison of the effects of dual chamber (DDD) and ventricular rate adaptive (VVIR) pacing on neuroendocrine variables, exercise performance, and symptoms in complete heart block. $\mathrm{Br}$ Heart F 1991;65:188-93.

10 Menozzi C, Brignole M, Moracchini PV, et al. Intrapatient comparison between chronic VVIR and DDD pacing in comparison between chronic VVIR and DDD pacing in patients affected by high degree AV block without heart 1816-22.

11 Sulke N, Chambers J, Dritsas A, Sowton E. A randomised double-blind crossover comparison of four rareresponsive pacing modes. $\mathcal{f} \mathrm{Am}$ Coll Cardiol 1991;17: 696-706.

12 Lukl J, Doupal V, Heinc P. Quality-of-life during DDD and dual sensor VVIR pacing. PACE Pacing Clin Electrophysiol 1994;17:1844-8.

13 Lau CP, Tai Y-T, Lee PWH, Cheung B, Tang M-O, Lam W-K. Quality-of-life in DDDR pacing: atrioventricular synchrony or rate adaptation? $P A C E$ Pacing Clin Electrophysiol 1994;17:1838-43.

14 Wiksrand J. Diastolic function of the hypertrophied left ventricle in primary hypertension. Clin Physiol 1986;6: 115-27.

15 Kuo LC, Quinones MA, Rokey R, Sartori M, Abinader EG, Zoghbi WA. Quantification of atrial contribution to left ventricular filling by pulsed Doppler echocardiography and the effects of age in normal and diseased hearts. Am 7 Cardiol 1987;59:1174 8 .

16 Collins KJ, Exton-Smith AN, Jams MH, Oliver DJ Functional changes in autonomic nervous responses with ageing. Age Ageing 1980;9:17-24.

17 Katritsis D, Camm AJ. Chronotropic incompetence: a proposal for

8 Carr KW, Engler RL, Forsythe JR, Johnson AD, Gosink B. Measurement of left ventricular ejection fraction by mechanical cross-sectional echocardiography. Circulation 1979;59:1196-206.

19 Griffin J, Spencer W, Cashion R, Nielsen A, Shuenemeyer $T$. Exercise capability of patients receiving DDD pacemakers [abstract]. PACE Pacing Clin Electrophysiol 1984; 7:460.

20 Channon KM, Hargreaves MR, Cripps TR, Gardner M, Ormerod OJM. DDD vs VVI pacing in patients aged over 75 years with complete heart block: a double blind crossover comparison. $Q \mathcal{F} M e d$ 1994;87:245-51.

21 Sulke N, Dritsas A, Bostock J, Wells A, Morris R, Sowton E. "Subclinical" pacemaker syndrome: a randomised study of symptom free patients with ventricular demand study of symptom free patients with ventricular demand Heart $\tilde{f} 1992 ; 67: 57-64$

22 Liebert H, O'Donoghue S, Tullner W, Platia E. Pacemaker syndrome in activity-responsive VVI pacing. Am f Cardiol 1989;64:124-6.

23 Wish M, Cohen A, Swartz J, Fletcher R. Pacemaker syndrome due to a rate-responsive ventricular pacemaker. $\mathcal{F}$ Electrocardiol 1988;2:504-7.

24 Jordaens L, de Backer G, Clement DL. Physiologic pacing in the elderly. Effects on exercise capacity and exerciseinduced arrhythmias. Fpn Heart F 1988;29:35-44.

25 Lau CP, Wong CK, Leung WH, Liu WX. Superior cardiac hemodynamics of atrioventricular synchrony over rate responsive pacing at submaximal exercise: observations in activity sensing DDDR pacemakers. observations in activity sensing DDDR pacem
PACE Pacing Clin Electrophysiol 1990;13:1832-7.

26 Rediker DE, Eagle KA, Homma S, Gillam LD, Harthorne JW. Clinical and hemodynamic comparison of VVI versus DDD pacing in patients with DDD pacemakers. $A m f$ Cardiol 1988;61:323-9.

27 Erlebacher JA, Danner RL, Stelzer PE. Hypotension with ventricular pacing: an atrial vasodepressor reflex in human beings. $7 \mathrm{Am}$ Coll Cardiol 1984;4:550-5.

28 Witte J, Blondke H, Muller S. The pacemaker syndrome: a haemodynamic complication of ventricular pacing. Cor Vasa 1988;30:393-9. 